\title{
Optimización del proceso de compostaje de productos post-cosecha (cereza) del café con la aplicación de microorganismos nativos
}

\author{
María Cristina Vásquez de Díaz, Paula A Prada P, Maritza A Mondragon A.
}

Universidad de Santander-UDES, Campus Universitario Lagos del Cacique, Bucaramanga, Colombia.

Correspondencia: mariacristinavr@gmail.com

Recibido: 18-09-10 / Aceptado: 12-12-10

\section{Resumen}

El cultivo del café trae consigo la producción de grandes cantidades de residuos pos-cosecha, como la cereza. Este desecho causa problemas ambientales debido a que contamina fuentes hídricas y genera alteraciones en el ecosistema cuando no es tratado adecuadamente. Una alternativa a este problema es la utilización de la cereza para la producción de abono orgánico, reduciendo los costos de producción. Este estudio tiene como objetivo disminuir el tiempo de compostaje de la cereza del café utilizando 3 consorcios bacterianos de cepas aisladas de la cereza, a través de la bio-aumentación.

En estos estudios se obtuvo compost que cumple con los parámetros exigidos por la NTC 5167 del 2004 y la resolución 00150 de enero de 2003 del ICA en 40 días.

Se observaron diferencias significativas entre la biopila testigo en los parámetros fisicoquímicos y los obtenidos en la pruebas bajo tratamiento con los consorcios bacterianos en 40 días, $\mathrm{pH}(\mathrm{P}=0,00552)$, en cuanto a la relación $\mathrm{C} / \mathrm{N}(\mathrm{P}=0,00$ 197)demostrando una madurez a los 40 días del estudio, Potasio $(\mathrm{P}=$ 0,0 I 2 I3), Fosforo total $(P=0,09547)$, Hierro total $(P=0,04502)$, Nitrógeno orgánico $(P=0,0042$ I $)$ elementos de gran importancia que contribuyen al desarrollo radicular y crecimiento de las plantas.

Palabras claves: cereza, contaminación, compostaje, bacterias nativas, bioaumentación.

\section{Abstract. \\ Composting process optimization of post-harvest product (cherry) coffee with the implementation of native micoorganisms \\ Coffee growing brings the production of large amounts of post-harvest residues such as cherry. This waste causes environmental problems due to contaminated water sources, and generates changes in in the ecosystem if not properly treated. An alternative to this problem is the use of the cherry for the production of compost, reducing production costs. This study aims to reduce composting time of the coffee cherry using 3 pools of bacterial strains isolated from cherry, through bio-augmentation.}


These studies obtained compost that meets the parameters required by the NTC 5167, 2004 and resolution 00150 January 2003 the ICA in 40 days. Significant differences between biocell witness in the physicochemical parameters and those obtained in the tests under treatment with bacterial consortia in 40 days, $\mathrm{pH}(\mathrm{P}=0.00552)$, as to the $\mathrm{C} / \mathrm{N}(\mathrm{P}=0,00$ 197) showing a maturity of 40 days of the study, potassium $(P=0.01213)$, total phosphorus $(P=0.09547)$, total iron $(P=0.04502)$, organic nitrogen $(P=0.0042 \mathrm{I})$ very important elements that contribute to root development and plant growth. Keywords: cherry, pollution, composting, native bacteria, bioaugmentation.

\section{Introducción}

El hombre con su actividad económica industrial y/o agrícola genera una gran cantidad de residuos que con frecuencia ocasionan importantes problemas ambiéntales por su almacenamiento y tratamiento inadecuado. 1 Una de las actividades agroindustriales que genera grandes volúmenes de residuos con mayor impacto negativo en Suramérica es la relacionada con el beneficio del café; en este continente se encuentran dos de los mayores productores de café a nivel mundial: Brasil y Colombia.

De las cosechas de café resultan miles de toneladas de residuos, pulpa o cereza mucílago, así como de pergamino (cascarilla), los cuales tienen gran potencial contaminante. El manejo de la pulpa de café ha sido uno de los más difíciles siendo el desecho de mayor volumen, que se acumula por períodos largos y conlleva a la generación de malos olores, siendo un medio propicio para la reproducción de moscas y otras plagas responsables de múltiples enfermedades. Por esto, un uso práctico de estos subproductos es la elaboración de abono orgánico que aporta nutrición a los cafetales y suelos de los cultivos en las áreas rurales. 2

En el 2008, Colombia como primer exportador mundial de café suave, produjo un promedio de 12.524 de sacos de café, cada uno de $60 \mathrm{~kg}$, lo que significó un volumen tanto solo del $20 \%$ de parte utilizable, lo que produjo un total de 3.005 toneladas de pulpa del café correspondiente al $80 \%$ de desechos, lo cual generó un problema ambiental y económico para los agricultores del grano.
Por estas razones y con el fin de disminuir el efecto negativo del proceso biológico aeróbico de la pulpa del café, se ha empleado la técnica del compostaje mediante la cual, los microorganismos actúan sobre la materia biodegradable3. Este proceso tarda normalmente de 5 a 9 meses, tiempo en el cual se alcanza el grado de madurez al realizar la biotransformación, mineralización o degradación completa de la pulpa del café. 4 La descomposición total de las moléculas orgánicas en dióxido de carbono, residuos inorgánicos inertes o minerales se incorporan de nuevo a la estructura del suelo para ser asimilados por los microorganismos y las plantas. El producto final de este proceso llamado compost, es rico en nutrientes como nitrógeno, fósforo y bacterias y puede ser aplicado nuevamente a los cultivos de café para la recuperación de suelos, lo que favorece el crecimiento vegetal y ayuda a convertir los suelos infértiles en fértiles. Sin embargo, este proceso puede resultar muy lento y costoso por la mano de obra para la mayoría de los cultivadores, por lo cual es necesario buscar formas de acelerar el proceso sin que desmejore la calidad del producto y que permita aumentar los beneficios finales como es la obtención de un sustrato orgánico de buena calidad al finalizar el tratamiento. 5

Una de estas formas se basa en la aceleración del proceso utilizando microorganismos nativos de compostaje de residuos post cosecha del café (pulpa), aplicando la técnica de bioaumentación. Con la disminución del tiempo de compostaje, 150 días a 40 días, a partir de la pulpa del café utilizando microorganismos nativos propios para 
lograr una rápida aceleración del proceso, se logró obtener un compost con los niveles adecuados de los parámetros físico-químicos exigidos por la Norma Técnica Colombiana (NTC 5167-2004). 6 Este producto podrá ser utilizado en las cosechas de café para producir un café orgánico de gran calidad, con beneficios económicos, tanto para el productor como para el comprador. 7

La producción de compost acelerado a partir de la pulpa del café contribuirá a la conservación y recuperación del ecosistema, pues en el proceso no se generan desechos como producto del tratamiento ya que los agentes contaminantes son realmente degradados, absorbidos o atrapados en los poros de éste, 8-9 su aplicación dará valor agregado a la agroindustria colombiana cuya actividad más importante es el cultivo del café. Teniendo en cuenta lo anterior, el objetivo de este trabajo fue acelerar el proceso de compostaje de residuos postcosecha del café (pulpa) mediante la inoculación de microorganismos nativos a fin de disminuir el tiempo de compostaje y obtener un compost de alta calidad que cumpliera con los parámetros exigidos por la por la Norma Técnica Colombiana 5167 del 2004.

\section{Materiales y métodos}

Se llevó a cabo un estudio experimental comparativo mediante una prueba de campo en un periodo de 40 días.

Área de estudio y muestra. El ensayo se realizó en la Subestación Experimental Santander de CENICAFÉ, localizada en el Km. 14 de la vía Bucaramanga - Cúcuta, donde se llevó a cabo el montaje de las pilas de la pulpa del café.

Muestra: pilas conformadas por $150 \mathrm{~kg}$ de pulpa del café. Las muestras fueron procesadas y analizadas en los Laboratorios del programa de Bacteriología y Laboratorio Clínico de la Universidad de Santander (UDES) en la ciudad de Bucaramanga-Colombia.

El plan de trabajo se realizó en dos fases.

\section{Primera fase}

Se prepararon medios de pre-enriquecimiento en medio basal de sales $(\mathrm{NaCl} 0.15 \mathrm{~g}$, (NH4)2SO4 0.3g, K2HPO40.37 g, KH2PO4 0.125 g, MgSO4.7H2O
$0.075 \mathrm{~g}, \mathrm{KNO} 30.3 \mathrm{~g}$ ) al que se le adicionaron $100 \mathrm{gr}$ de la muestra en estudio. Posteriormente, se agitaron en forma continua (120 r.p.m) durante 12 días. A partir del séptimo día se realizaron siembras por agotamiento en Agar MacConkey, Agar Tripticasa de Soya, Agar Malta, para lograr el aislamiento de bacterias y hongos, para luego ser utilizados en el proceso de aceleración del compostaje. Se realizó coloración de Gram, Oxidasa y series bioquímicas para la identificación de los microorganismos aislados. Se mantuvieron las cepas en caldo Brain-Heart Infusion (BHI), para luego efectuar pruebas de competitividad y compatibilidad entre los diferentes microorganismos aislados. Brevemente, fueron realizadas siembras en agar modificado con diferentes grupos de microorganismos en forma masiva hasta la mitad de la caja con una cepa A e incubada a $37^{\circ} \mathrm{C}$ por 24 horas; luego en la mitad no sembrada se realizó una estría perpendicular con otra cepa $B$ y se incubó en las mismas condiciones. Con los resultados obtenidos se determinaron los microorganismos compatibles y se conformaron los consorcios para ser aplicados durante el proceso de compostaje. Finalmente, se prepararon caldos modificados mediante fermentación discontinua a partir de un volumen de $100 \mathrm{~mL}$, los cuales se transfirieron a un volumen de $500 \mathrm{~mL}$ y luego a $3000 \mathrm{~mL}$ hasta obtener una concentración final de $108 \mathrm{ufc} / \mathrm{mL}$. (10)

\section{Segunda fase}

Montaje de las pruebas de campo. Se realizaron los montajes de 5 pilas de compostaje con un volumen de $175 \mathrm{Kg} .4$ pilas fueron inoculadas con microorganismos y una no (control negativo-sin inóculo). Se aplicaron los pooles bacterianos en los días 1, 10, 20 y 30; adicionalmente se realizó volteó en cada uno de estos días, monitoreo de los parámetros físico-químicos ( $\mathrm{pH}$, temperatura y humedad) y microbiológicos (recuento de microorganismos viables) fueron realizados durante el ensayo. El día 40, se tomó muestra de cada una de las biopilas para los análisis físico-químicos: Nitrógeno (Semi-micro Kjeldah)1; Fósforo (colorimétrico-Molibdobanadato de Amonio); Potasio, Calcio, Magnesio, Hierro, Manganeso, Zinc y Cobre (Espectrofotometría de absorción atómica); Boro (colorimétrico-Azometina $\mathrm{H}$, $\mathrm{pH}$ (potenciométrico); humedad (secado a 
Tabla 1. Variable comportamiento microbiano.

\begin{tabular}{llllll} 
& CONTROL & BIOPILA 1 & BIOPILA 2 & BIOPILA 3 & p-value \\
\hline Carbono orgánico oxidable. Total (\%) & 23 & 23.4 & 19.6 & 22 & 0.35248 \\
pH (Pasta de saturación. & 9.6 & 8.6 & 8.72 & 8.46 & 0.00552 \\
$\begin{array}{l}\text { Capacidad de intercambio catiónico. } \\
\text { (me/100g.) }\end{array}$ & 30 & 68.9 & 53.3 & 54.6 & 0.02856 \\
Relación carbono /nitrógeno & 23 & 10 & 10 & 10 & 0.00197 \\
Nitrógeno orgánico (NOrg) (\%) & 1 & 2.33 & 2.06 & 2.21 & 0.00421 \\
Fósforo Total (P2O5) (\%) & 0.6 & 0.76 & 0.76 & 0.64 & 0.09547 \\
Potasio Total (K2O) (\%) & 3.5 & 5.5 & 5.01 & 4.91 & 0.01213 \\
Calcio Total (CaO) (\%) & 1 & 1.2 & 1.18 & 1.07 & 0.06871 \\
Magnesio Total $(\mathrm{MgO})(\%)$ & 0.8 & 0.3 & 0.33 & 0.29 & 0.00059 \\
Hierro Total $(\%)$ & 0.22 & 0.57 & 0.9 & 0.61 & 0.04502 \\
\hline
\end{tabular}

$105^{\circ} \mathrm{C}$ ) realizados en los laboratorios de Control de CENICAFE en Chinchiná-Caldas (Colombia) y microbiológicos: recuento de microorganismos viables; calidad sanitaria -recuento de Coliformes totales y Escherichia coli y Salmonella spp. del producto obtenido (10-12).

\section{Determinación de microorganismos patógenos y calidad sanitaria}

Número Más Probable (NMP). El número más probable (NMP) se determinó mediante un método rápido y específico en el caldo Fluorocult LMX, que reduce el número de falsos positivos.

Determinación de Salmonella spp. Se realizó pre-enriquecimiento no selectivo con 11 gr. de cada muestra adicionados a $99 \mathrm{ml}$ de agua peptonada e incubados a $37^{\circ} \mathrm{C}$ por 24 horas. Posteriormente, se adicionó $1 \mathrm{ml}$ de la dilución anterior a $9 \mathrm{ml}$ de caldo Rappaport que fue incubado en un baño serológico a $43^{\circ} \mathrm{C}$. Por último, una asada se sembró en medio Rambach y se incubó por 24 horas. A las colonias compatibles les debe realizar pruebas bioquímicas con el sistema BBL-Cristal NF.

El recuento de microorganismos viables se realizó por el método de profundidad en placa, mediante diluciones de la muestra de 101 a 107 en agua peptonada al $0.1 \%$ y siembras de $1 \mathrm{ml}$ en agar recuento, que luego fueron incubadas a $37^{\circ}$ por 24 horas.

Se analizaron las variables $\mathrm{pH}$, humedad y comportamiento mediante un modelo de regresión lineal mixto para un diseño de bloques completos al azar, donde el efecto de bloque es dado por el tiempo y se considera aleatorio. El tratamiento experimental fue evaluar el tipo de biopila, que es considerado un efecto fijo. Se realizaron múltiples comparaciones entre todos los tratamientos ajustando los valores $P$ por el método de Tukey y Kramer. 11-12

\section{Resultados}

Se aislaron e identificaron microorganismos nativos de la pulpa del café involucrados en el proceso de biodegradación tales como Pseudomonas spp, Citrobacter koseri, Bacillus spp., Escherichia coli, Stenotrophomona maltophilia, Cromobacterium spp, Klebsiella oxytoca. En la Tabla 1 se presentan los resultados de evaluación de los parámetros de comportamiento microbiano y en la Tabla 2 los parámetros físico-químicos en 4 biopilas. El producto final, Tabla 3, se obtuvo con buen contenido de carbono orgánico oxidable y por ello es una buena fuente de materia orgánica, como lo demostró la relación $\mathrm{C} / \mathrm{N}$ en la pila 1 con $9,6 \%$, en la pila 2 con $10,0 \%$ y en la pila 3 con $9,5 \%$. Al comparar estos resultados con los de la referencia $(<20 \%)$, las pilas aseguran estabilidad y madurez en menor tiempo. El modelo permitió hacer múltiples comparaciones ajustando los valores $P$, Tabla 1 .

Basados en este modelo se observaron diferencias significativas en el logaritmo del comportamiento microbiano entre las biopilas y la biopila testigo al final del periodo experimental de 40 días. 
Tabla 2. Resultados de la evaluación de los parámetros químico-físicos en cuatro biopilas.

\begin{tabular}{|c|c|c|c|c|c|}
\hline PARAMETRO & BIOPILA 1 & BIOPILA 2 & BIOPILA 3 & BIOPILA 4 & $\begin{array}{c}\text { SUSTRATO } \\
\text { ORGÁNICO } \\
\text { (NORMA } 5167 \text { ICA }\end{array}$ \\
\hline HUMEDAD & $20,0 \%$ & $20,0 \%$ & $20,0 \%$ & $20, \%$ & $<=40 \%$ \\
\hline CENIZAS & $27,1 \%$ & $34,4 \%$ & $31,4 \%$ & - & Mayor de $15 \%$ \\
\hline $\begin{array}{l}\text { PERDIDA POR } \\
\text { VOLATILIZACION }\end{array}$ & $52,9 \%$ & $45,5 \%$ & $48,5 \%$ & - & \\
\hline $\begin{array}{l}\text { CARBOBO } \\
\text { ORGANICO } \\
\text { OXIDABLE TOTAL }\end{array}$ & $23,4 \%$ & $19,6 \%$ & $22,0 \%$ & $3 \%$ & Mayor de $0.5 \%$ \\
\hline $\begin{array}{l}\text { pH (PASTA DE } \\
\text { SATURACION) }\end{array}$ & 8,6 & 8,72 & 8,46 & 9,6 & $\begin{array}{l}\text { Mayor de } 1.5 \% \text { Menor } \\
\text { de } 9\end{array}$ \\
\hline $\begin{array}{l}\text { DENSIDAD (BASE } \\
\text { SECA-20C) }^{\circ}\end{array}$ & $0,5 \mathrm{~g} /$ c.c. & $0,72 \mathrm{~g} / \mathrm{c.c}$. & $0,71 \mathrm{~g} /$ c.c. & 0,90 & Mayor de 9\% \\
\hline $\begin{array}{l}\text { CONDUCTIVIDAD } \\
\text { ELECTRICA }\end{array}$ & $15,7 \mathrm{dS} / \mathrm{M}$ & $16,3 \mathrm{dS} / \mathrm{M}$ & $16,1 \mathrm{dS} / \mathrm{M}$ & - & Mayor de $0.75 \%$ \\
\hline $\begin{array}{l}\text { RETENCION DE } \\
\text { HUMEDAD }\end{array}$ & $220 \%$ & $206 \%$ & $217 \%$ & - & $35-45 \%$ \\
\hline $\begin{array}{l}\text { CAP. INTERCAMBIO } \\
\text { CATIONICO }\end{array}$ & $\begin{array}{l}6 \quad 8 \quad 9 \\
(\mathrm{me} / 100 \mathrm{gr})\end{array}$ & $\begin{array}{l}54,3 \\
(\mathrm{me} / 100 \mathrm{gr})\end{array}$ & $\begin{array}{l}54,6 \\
(\mathrm{me} / 100 \mathrm{gr})\end{array}$ & $\begin{array}{l}3 \quad 0 \\
(\mathrm{me} / 100 \mathrm{gr})\end{array}$ & $\begin{array}{l}\text { M a y o r } \\
30 \mathrm{meq} / 100 \mathrm{gr}\end{array}$ \\
\hline RELACION C/N & 10 & 10 & 10 & 23 & $<20 \%$ \\
\hline $\begin{array}{l}\text { NITROGENO } \\
\text { ORGANICO (Norg) }\end{array}$ & $2,33 \%$ & $2,06 \%$ & $2,21 \%$ & - & $1.15-1.5 \%$ \\
\hline $\begin{array}{l}\text { FOSFORO TOTAL } \\
(\mathrm{P} 2 \mathrm{O} 5)\end{array}$ & $0,76 \%$ & $0,76 \%$ & $0,64 \%$ & $0,6 \%$ & Menor de 0.6 \\
\hline $\begin{array}{l}\text { POTASIO TOTAL } \\
(\mathrm{K} 20)\end{array}$ & $5,50 \%$ & $5,01 \%$ & $4,91 \%$ & $3,5 \%$ & \\
\hline $\begin{array}{l}\text { CALCIO TOTAL } \\
(\mathrm{CaO})\end{array}$ & $1,20 \%$ & $1,18 \%$ & $1,07 \%$ & $1,0 \%$ & \\
\hline $\begin{array}{l}\text { MAGNESIO TOTAL } \\
(\mathrm{MgO})\end{array}$ & $0,30 \%$ & $0,33 \%$ & $0,29 \%$ & $0,80 \%$ & \\
\hline AZUFRE TOTAL & $0,29 \%$ & $0,26 \%$ & $0,25 \%$ & - & \\
\hline HIERRO TOTAL & $0,57 \%$ & $0,90 \%$ & $0,61 \%$ & - & \\
\hline $\begin{array}{l}\text { MANGANESO } \\
\text { TOTAL }\end{array}$ & 104 p.p.m & 112 p.p.m & 104 p.p.m & - & \\
\hline COBRE TOTAL & 24 p.p.m & 26 p.p.m & 20 p.p.m & - & \\
\hline ZINC TOTAL & 66 p.p.m & 52 p.p.m & 34 p.p.m & - & \\
\hline BORO TOTAL & 47 p.p.m & 46 p.p.m & 43 p.p.m & - & \\
\hline SODIO TOTAL & $0,03 \%$ & $0,03 \%$ & $0,02 \%$ & - & \\
\hline $\begin{array}{l}\text { SILECE TOTAL SiO2 } \\
\text { (SOLIDO SOLUBLE } \\
\text { EN HF) }\end{array}$ & $11,10 \%$ & $18,4 \%$ & $17,8 \%$ & - & \\
\hline
\end{tabular}


Resaltamos diferencias significativas en las características fisicoquímicas y parámetros de importancia exigidos por la norma técnica colombiana como son en $\mathrm{pH}(\mathrm{P}=0,00552)$, en cuanto a la relación $\mathrm{C} / \mathrm{N}(\mathrm{P}=0,00197)$ demostrando una madurez a los 40 días del estudio, Potasio $(\mathrm{P}=0,01213)$, Fosforo total $(\mathrm{P}=0,09547)$, Hierro total $(\mathrm{P}=0,04502)$, Nitrógeno orgánico $(\mathrm{P}=0,00421)$ elementos de gran importancia que contribuyen al desarrollo radicular y crecimiento de las plantas.

La investigación permitió demostrar experimentalmente que es posible acelerar el proceso de compostaje utilizando microorganismos nativos de la pulpa del café y disminuir a 40 días el tiempo requerido para obtener un sustrato orgánico de buena calidad al finalizar el tratamiento, ajustado a la Norma técnica colombiana NTC 5167-2003, que regula los materiales orgánicos usados como fertilizantes y acondicionadores de suelos en Colombia.

La eficiencia lograda fue de $32,0 \%$ en la pila $1,35.9$ $\%$ en la pila 2, 38,6 \% en la pila 3 con unos pesos de producto final entre 32 y $38,6 \mathrm{Kg}$, mientras que por el proceso de compostaje natural con lombricultura se obtienen eficiencias entre $8,0 \%$ y $10,0 \%$. De la misma manera, se logró un abono orgánico con la calidad sanitaria exigida por la Resolución 00150 de Enero de 2003 que consta de coliformes totales, coliformes fecales, aerobios mesófilos y Salmonella. El análisis estadístico de los resultados mostró diferencias significativas con el uso de consorcios a partir de microrganismos nativos, por lo que se propone seguir trabajando con el consorcio No. 1 Pseudomonas spp.- Stenotrophomona maltophilia y el consorcio No. 3 Citrobacter koseri y Pseudomonas aeruginosa, en los cuales se observaron los mejores resultados.

Finalmente, a partir de los residuos de la pulpa del café se obtuvo un compost en 40 días que cumple con los parámetros exigidos por la norma técnica Colombiana (NTC 5167, 2004) para ser utilizado como abono orgánico en el cultivo del café, lo que podría contribuir a la conservación y recuperación del ecosistema en las zonas cafeteras del país.

Se observaron diferencias significativas entre la biopila testigo en los parámetros fisicoquímicos y los obtenidos en la pruebas bajo tratamiento con los consorcios bacterianos en 40 días, $\mathrm{pH}(\mathrm{P}=0,00552)$, en cuanto a la relación $\mathrm{C} / \mathrm{N}(\mathrm{P}=0,00197)$ demostrando una madurez a los 40 días del estudio, Potasio ( $\mathrm{P}=$ $0,01213)$, Fosforo total $(\mathrm{P}=0,09547)$, Hierro total $(\mathrm{P}=$ $0,04502)$, Nitrógeno orgánico $(P=0,00421)$ elementos de gran importancia que contribuyen al desarrollo radicular y crecimiento de las plantas.

\section{Agradecimientos}

Se agradece especialmente al Ingeniero Agrónomo Pedro María Sánchez, a Liliana García Torcoroma, Bacterióloga Phd., Wilfredo Valdivieso, Bacteriólogo M.Sc. del grupo de investigaciones de la Universidad de Santander.

A la Universidad de Santander y su directora Libeth Yahaira Criado G., Bacterióloga M.Sc. por el apoyo continuo en los procesos de investigación.

\section{Referencias}

1. Moreno C. y Moral HR. Compostaje. España, Mundi Prensa. 2007, p.370.

2. Blandion CG, Davila AMT, Rodríguez VN. Caracterización microbiológica y Físico-Química de subproductos de beneficio del café en proceso de compostaje. Revista Cenicafe. 1999;50(1):5-22.

3. Araujo I, Angulo N, Cárdenas C, Méndez M, Morantes M. Biorremediación de suelos con consorcios bacterianos compostaje y fertilización biológico. Venezuela. 2005;31(4):268-275.

4. Farfán VF,Residuos de la producción cafetera para la producción y su uso como abonos orgánicos. Fitotecnia. CENICAFE, 2002. Consultado en Febrero 2009. Disponible en: http://www.ucentral.edu.co/pregrado/ escuelainge/hidricos/memorias/taller\%20abonos\%20org\%E1nicos.pdf

5. Soto G, Muñoz C. Manejo Integrado de Plagas y Agroecología Consideraciones teóricas y prácticas sobre el compost y su empleo en la agricultura Orgánica. Costa Rica. 2002;65:123-9.

6. NTC 5167-2004: Productos para la industria agrícola. Productos orgánicos usados como abonos o fertilizantes y enmiendas de suelo.

7. Canovas, A. Tratado de Agricultura Ecológica. Almería. Editorial Instituto de Estudios Almerienses de la Diputación de Almería. 1993: p.190.

8. Federación Nacional de Cafeteros de Colombia. Centro Nacional de Investigación de Café - CENICAFÉ. Cartilla cafetera. Tomo II. Bogotá. Editorial FNC. 2004

9. Cepeda PL y Valencia CS. Aislamiento de bacterias lipolíticas y determinación de patógenos humanos Escherichia coli y Salmonella sp. a partir de residuos orgánicos domiciliarios en compostaje. [Tesis de pregrado opta por el titulo Microbiología Industrial]. Bogotá, Pontificia Universidad Javeriana, Colombia; Julio; 2007.

10. Littel R., Milliken G., Stroup W., Wolfinger R., Schabenberger O. 2006. SAS for Mixed Models. Second Ed., SAS Institute, Cary, NC.

11. Littel R., Pendergast J., Natarajan R. 2002. Modelling Covariance Structure in the Analysis of Repeated Measures Data. Statistics in Medicine 19:1793-1819. 
12. Moreno CJ y Mormeneo B S. Microbiología y bioquímica del proceso del compostaje. Editorial. Mundiprensa. Universidad Valencia España. 2008: p. $115-160$.

13. Narváez FS, Martínez M, Gómez M. Selección de Bacterias con capacidad degradadora de hidrocarburos aisladas a partir de sedimentos del Caribe Colombiano. Bol. Invermar. 2008;37(1):21-4.

14. Ospina S., O.; Farfan V., F. Potencial para la producción y certificación de café orgánico en fincas del Departamento de Caldas (Revista Cenicafe 54(2):145-160. 2003 (Es)). ++ Dat.num. 9 ref. Sum (En, Es). *EC-INIAP-BEETP, Quevedo (Rev/Cenicafe 54(2):145-160).

15. Vàsquez Mc, Thibisay $\mathrm{J}$, Quintero $\mathrm{A}$, Biorremediaciòn de lodos contaminados con aceites lubricantes usados, Revista Colombiana de Biotecnologia, Vol XII, Numero 1-Julio 2010,p141-157

16. Guiberteau, A.; Labrador, J. (1991). Técnicas de cultivo en Agricultura Ecológica. En: Hoja Divulgadora Num. 8/91 HD. Ministerio de Agricultura, Pesca y Alimentación. Madrid. 44 pp.
17. Porta, J; López-Acevedo, M; Roquero, C. 1994. Edafología para la agricultura y el medio ambiente. Ed. Mundi-Prensa. Madrid. 807 pp.

18. „B. La Microbiología del suelo en la era de la Biología Molecular, en la punta del iceberg..Mayo2005, http://www.revistaecosistemas.net/ articulo.asp?id $=116$

19. Moreno,C.J, Mormeneo,BS, Microbiología y bioquímica del proceso del compostaje. Mundiprensa,2008;9: 115-160.

20. Medina P, Almudena. (2006) Estudio de la acción entre inoculantes microbianos y residuos agroindustriales biotransformados para su uso en estrategias de revegetación y biorremediación. Granada: Universidad de Granada,p.272.

21. Montilla-Pérez Ximena; Arcila-Pulgarín Jaime y col. Propiedades Físicas y Factores de Conversión del Café en el Proceso de Beneficio. CENICAFE. 2008 